\title{
Invigorating Prescribed Fire Science Through Improved Reporting Practices
}

\section{OPEN ACCESS}

Edited by:

Guillermo Emilio Defossé,

Consejo Nacional de Investigaciones Cientificas y Técnicas (CONICET),

Argentina

Reviewed by:

Carlos Roberto Kunst,

Instituto Nacional de Tecnología Agropecuaria, Argentina

Nuria Prat-Guitart,

Fundación Pau Costa, Spain

*Correspondence:

Sophie R. Bonner

sophie.bonner.eco@gmail.com

Specialty section: This article was submitted to

Fire and Forests,

a section of the journal Frontiers in Forests and Global

Change

Received: 31 July 2021 Accepted: 06 October 2021 Published: 27 October 2021

Citation:

Bonner SR, Hoffman CM, Kane JM, Varner JM, Hiers JK, O'Brien JJ, Rickard HD, Tinkham WT,

Linn RR, Skowronski N, Parsons RA and Sieg CH (2021) Invigorating Prescribed Fire Science Through Improved Reporting Practices.

Front. For. Glob. Change 4:750699. doi: 10.3389/ffgc.2021.750699

\begin{abstract}
Sophie R. Bonner ${ }^{*}$, Chad M. Hoffman ${ }^{1}$, Jeffrey M. Kane' ${ }^{2}$ J. Morgan Varner ${ }^{3}$, J. Kevin Hiers ${ }^{3}$, Joseph J. O'Brien", Heather D. Rickard², Wade T. Tinkham', Rodman R. Linn ${ }^{5}$, Nicholas Skowronski ${ }^{6}$, Russell A. Parsons ${ }^{7}$ and Carolyn H. Sieg ${ }^{8}$

${ }^{1}$ Department of Forest and Rangeland Stewardship, Colorado State University, Fort Collins, CO, United States, ${ }^{2}$ Department of Forestry and Wildland Resources, Humboldt State University, Arcata, CA, United States, ${ }^{3}$ Tall Timbers Research Station, Tallahassee, FL, United States, ${ }^{4}$ Center for Forest Disturbance Science, Southern Research Station, USDA Forest Service, Athens, GA, United States, ${ }^{5}$ Los Alamos National Laboratory, Earth and Environmental Science Division, Los Alamos, NM, United States, ${ }^{6}$ Northern Research Station, USDA Forest Service, Morgantown, WV, United States, ${ }^{7}$ Fire Sciences Laboratory, Rocky Mountain Research Station, USDA Forest Service, Missoula, MT, United States, ${ }^{8}$ Rocky Mountain Research Station, Forest and Woodland Ecosystems, USDA Forest Service, Flagstaff, AZ, United States
\end{abstract}

Interest in prescribed fire science has grown over the past few decades due to the increasing application of prescribed fire by managers to mitigate wildfire hazards, restore biodiversity, and improve ecosystem resilience. Numerous ecological disciplines use prescribed fire experiments to provide land managers with evidence-based information to support prescribed fire management. Documenting variation in the context and conditions during prescribed fire experimental treatments is critical for management inference, but inconsistencies in reporting critical experimental details can complicate interpretation. Such details are needed to provide ecological and empirical context for data, facilitate experimental replication, enable meta-analyses, and maximize utility for other scientists and practitioners. To evaluate reporting quality in the recent literature, we reviewed 219 prescribed fire experiments from 16 countries published in 11 refereed journals over the last 5 years. Our results suggest substantial shortcomings in the reporting of critical data that compromise the utility of this research. Few studies had specific information on burning conditions such as fuel moisture (22\%), quantitative fuel loads (36\%), fire weather (53\%), and fire behavior (30\%). Further, our analysis revealed that $63 \%$ of the studies provided precise coordinates for their study area, while $30 \%$ of studies indicated the prescribed fire date. Only $54 \%$ of the studies provided descriptions of the ignition characteristics. Given these common deficiencies, we suggest minimum reporting standards for future prescribed fire experiments. These standards could be applied to journal author guidelines, directed to researchers and reviewers by the editor, and promoted in the education of fire ecologists. Establishing reporting standards will increase the quality, applicability, and reproducibility of prescribed fire science, facilitate future research syntheses, and foster actionable science.

Keywords: reporting guidelines, fire ecology, fire effects, ecological measurement, prescribed burning, wildland fire research 


\section{INTRODUCTION}

Across a diversity of terrestrial ecosystems, prescribed fire is commonly used to achieve a wide variety of land management objectives, including increasing biodiversity, improving wildlife habitat, and reducing woody encroachment, invasive species, and fuel and fire hazards (Fernandes and Botelho, 2003; Ryan et al., 2013; Stephens et al., 2021). Prescribed fire and its effects are influenced by a complex suite of interactions between the burning environment (e.g., fuels, fire weather, and topography), ignition characteristics, attributes of the specific organisms and ecosystems being studied, and a host of other moderating effects, including legacies of past disturbances, climatic conditions, soils, and land management practices (O'Brien et al., 2018). Given this complexity and the time constraints faced by managers, it can be challenging to critically evaluate, interpret, and apply what often appear to be contradictory findings among scientific studies. In cases where fire science guidance is unclear, it is common for managers to rely on past experiences rather than systematic evidence in the decision-making process (Pullin et al., 2004). Although the inclusion of local knowledge and personal experience in decision-making is an important aspect of land management, fire scientists and managers increasingly recognize the vital role that sound and repeatable science plays in developing robust evidence-based policies and land management decisions related to the use of prescribed fire (Hunter et al., 2020). Fire research has historically focused its efforts more on wildfires rather than prescribed fires, resulting in disparities in the amount of funding and volume of publications available compared to the global frequency and extent of prescribed fires (Hiers et al., 2020). Given the increased recommendations for prescribed fire use along with a paucity of prescribed fire research in many ecosystems, there is a need for research that improves our understanding of the underlying mechanisms driving the ecological effects of prescribed fires (O'Brien et al., 2018; Hiers et al., 2020).

To meet this need, investigations have increasingly utilized prescribed fire as a treatment in both controlled and natural ecological experiments using in situ space-for-time approaches and long-term monitoring. As the volume of prescribed fire research increases, there are new opportunities to advance our understanding of the broad-scale patterns, mechanisms, complex interactions, and contextual dependencies associated with prescribed fire effects through the development, refinement, and evaluation of models and the completion of systematic reviews and meta-analyses. Compared to more traditional narrative reviews and vote counting approaches (i.e., a tally of research manuscripts for or against a given hypothesis), systematic reviews and meta-analyses rely on reproducible quantitative methodologies to provide a more objective and informative synthesis of the existing literature (Cooke et al., 2017).

Although measurements and observations of prescribed fires are increasing, there are significant challenges to maximizing the utility of this information due to insufficient reporting of critical experimental details (Hillebrand and Gurevitch, 2013; Fernandes, 2018). Prescribed fire studies often use unique experimental designs and measurement protocols based on the specific response variable(s) of interest and the traditions and norms of the associated ecological subdiscipline. While variability in methodologies is expected (and in some senses required) given the breadth of subdisciplines that conduct prescribed fire experiments, this variation can lead to considerable inconsistency in how and which biotic and abiotic variables are measured during the experiment and reported in the literature. Moreover, managers conducting prescribed fire often have a specific objective, necessitating the control of timing, pattern, and pace of ignition. Inadequate reporting of methodological and contextual details such as these can hinder the readers' ability to verify and interpret the results, prevent replication of the experiment, and limit further syntheses of the data (Hillebrand and Gurevitch, 2013; Haddaway and Verhoeven, 2015).

Many ecological journals and funding agencies have recently increased author requirements to improve data archiving and availability, including requiring as a condition of publication that authors archive all data and code associated with the research in a public repository such as GitHub or Dryad (Reichman et al., 2011; Whitlock, 2011). While open data policies can vastly increase reproducibility, improve transparency, and support future repurposing of the data, they do not overcome deficiencies in reporting experimental details. A variety of other approaches can be helpful for improving the reporting of experimental details in the scientific literature. For previously published studies, searching for related studies or contacting the authors can often be a helpful approach for finding missing details (Haddaway and Verhoeven, 2015). Authors then can combine previously missing details and publish them with the original data and methods to support replication of the experiment and any future analyses. An increasingly common approach to reducing reporting deficiencies and fostering replicability is developing minimum reporting standards or guidelines (Hillebrand and Gurevitch, 2013; Vetter et al., 2016).

In this study, we present results from a literature review of prescribed fire experiments published in 11 ecological journals over the last 5 years to determine the degree to which experimental details are described. Based on the results of this literature review, we propose a set of minimum reporting guidelines for prescribed fire experiments in ecology and other related disciplines.

\section{MATERIALS AND METHODS}

We identified potential peer-reviewed journal articles for analysis using a Web of Science search for studies published over the 5-year period from January 2016 through December 2020. We first searched for studies that had the terms "prescribed fire" or "prescribed burn" or "controlled burn" or "controlled fire" or "hazard reduction burn" or "fuel reduction burn" or "experimental fire" in the title, keywords, or abstract. We excluded studies focused on "wildfires" or "combustion" from our search by including the "not" operator. Given that our primary interest was in the use of prescribed fire within the ecological literature, we used the "refine" function to exclude less relevant topical areas such as medicine, energy, and engineering. 
TABLE 1 | The number of published studies from 2016 through 2020 that report on an ecological prescribed fire experiment for the 11 journals evaluated.

\begin{tabular}{lc}
\hline Journal & Article count \\
\hline Forest Ecology and Management & 73 \\
Science of the Total Environment & 27 \\
Rangeland Ecology and Management & 20 \\
Forests & 18 \\
International Journal of Wildland Fire & 17 \\
Fire Ecology & 14 \\
Journal of Wildlife Management & 12 \\
Ecological Applications & 11 \\
Ecosphere & 11 \\
Natural Areas Journal & 9 \\
Fire & 7 \\
\hline Total & 219 \\
\hline
\end{tabular}

Additionally, we performed an identical search within the journal "Fire" published by Multidisciplinary Digital Publishing Institute (MDPI), which only began publishing in 2018 and was not indexed by Web of Science at the time of our search. We then identified the ten journals that most frequently published ecological prescribed fire studies (Table 1). Articles identified from these ten journals plus the journal "Fire" were used for all further analysis. We included studies that used prescribed fire as part of a controlled or natural experiment that addressed an ecological question for further analysis. We excluded studies that examined the cumulative ecological effects of repeated prescribed fires, studies performed in a laboratory, modeling experiments, and studies that primarily focused on quantifying the behavior of a free spreading fire or those focused on the ecological effects following a wildfire. At least two of the coauthors screened each study for inclusion and further analysis. In cases where coauthors disagreed about inclusion, a third co-author evaluated the article and made a final decision. The kappa test of agreement score for this screening was 0.66 , indicating that substantial agreement existed among coauthors (Cohen, 1960; Landis and Koch, 1977). This process resulted in 219 studies for further analysis (Table 1 and Supplementary Data 1).

For all 219 articles, we first recorded primary data including the authors, journal, country in which the prescribed fire experiment occurred, and publication year. We then evaluated each article for information on when and where prescribed fires were conducted, the ecological context, landscape position, ignition characteristics, and burning conditions based on the highest level of precision provided by the authors. For each study, we documented if the manuscript reported the location using specific coordinates or through a map of the burn unit. We also checked to see if authors reported on land use legacies for these locations, such as disturbance events (e.g., natural disasters, beetle infestations, disease, and drought) and historical land management practices (e.g., silvicultural treatments, livestock grazing, and farming). We classified timing based on the most precise category reported in the study (i.e., hour, day, month, season, and year) for which an exact unit was provided. For example, in a situation where a study reported a range of days in a given month, we classified the study as having reported to the month rather than to the day.

Given that fire effects are influenced by the ecological context, landscape position, and land use legacies associated with the experiment, it is imperative that this information be reported, especially for natural experiments where control of influencing factors was not possible. Although many abiotic and biotic variables can influence or moderate fire effects, we recorded how the authors described four common variables of interest: plant species composition, climate, topography, and soils for each study. We reviewed whether the plant species composition was reported using quantitative metrics (e.g., cover, tree density, and basal area), a qualitative description (i.e., plant list, plant associations, and habitat type), a cover type (e.g., Society of American Foresters; Eyre, 1980), or a physiognomic description (e.g., Faber-Langendoen et al., 2016). For climate, we noted whether studies reported a long-term climate average or a climate zone for their burn units. We recorded whether studies described the burn unit topography, including aspect, elevation, and slope. Additionally, we identified if the studies provided a description or linked to a description of the underlying soils.

We also evaluated reporting of the ignition characteristics and burning conditions for each study. We assessed ignition characteristics based on reporting of the ignition method (e.g., drip torch and helitorch), pattern (e.g., dash, dot, and line), technique (e.g., backing fire, flanking fire, and strip head fire), and duration of ignition (i.e., time taken to complete ignition). We assessed the reporting of fuels based on the use of a quantitative description of the fuels complex (e.g., fuel load and bulk density), a stylized fuel model or classification (e.g., Anderson, 1982; Scott and Burgan, 2005; Ottmar et al., 2007), or a qualitative description of the plant community or cover type. We also evaluated the reporting of weather conditions during the burn, including air temperature, relative humidity, wind speed, and fuel moisture. Finally, we assessed each study to see which metrics of fire behavior (e.g., flame lengths, rate of spread, residence time) they reported.

\section{RESULTS}

Our results identified 219 ecological prescribed fire experiments from the following 16 countries: United States of America (145), Spain (28), Australia (18), Canada (6), Finland (6), Sweden (3), Hungary (2), Kenya (2), Scotland (2), Brazil (1), Germany (1), Italy (1), Lebanon (1), Lithuania (1), Mexico (1), and Nepal (1).

The approach used to report spatial and temporal details varied among studies (Figure 1). All but one study provided information on the location of the burn unit. Approximately $12 \%$ of studies provided a name or description of the general burn unit location without further detail. One quarter (25\%) of the studies provided a map of the burn locations. In most cases, however, maps lacked sufficient detail to enable future studies to precisely identify the burn unit location. The remaining $63 \%$ of studies provided coordinates for their burn units. However, only $6 \%$ provided coordinates for sampling locations within a burn unit. Approximately $7 \%$ of studies supplied no temporal data for 


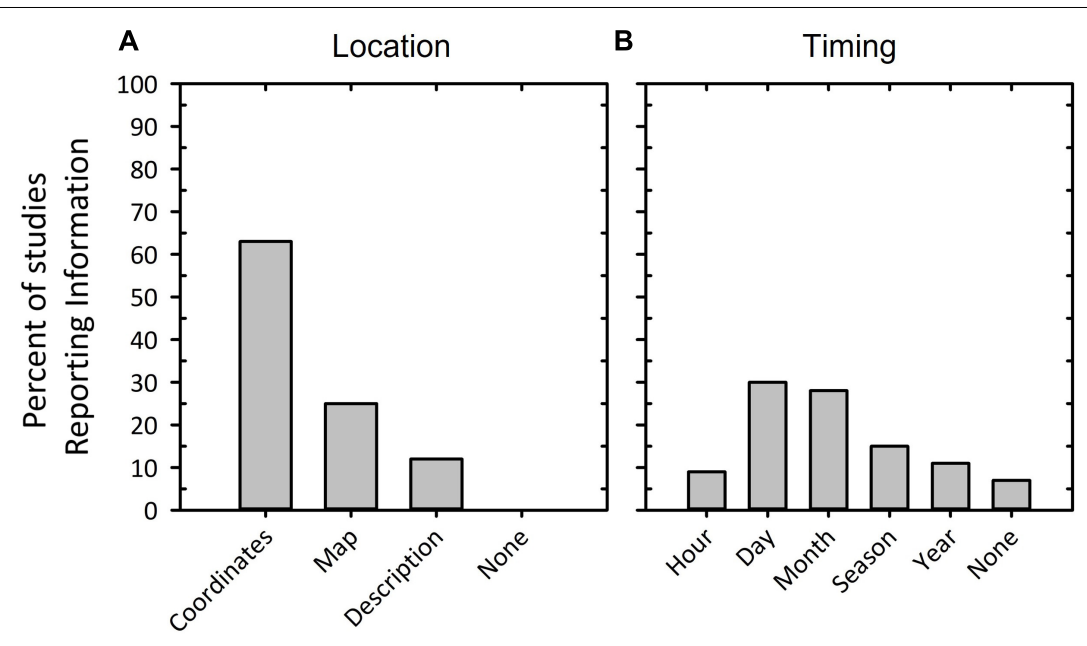

FIGURE 1 | Plots showing the level of precision to which authors reported (A) the location of burn and (B) the timing of burn in recent prescribed fire studies.

prescribed fire: $9 \%$ provided the hour, $30 \%$ provided the day, $28 \%$ the month, $15 \%$ the season, and $11 \%$ provided only the burn year.

Most studies provided details describing the prescribed fire's ecological context and landscape position, with only one study failing to report any details on plant species composition, climate, topography, or soils. All but one study reported plant species composition, although the reporting quality varied (Figure 2A). Nearly $4 \%$ of studies described plant species composition using a basic physiognomic description and $10 \%$ reported a cover type (Figure 2A). The remaining studies provided either a qualitative (45\%) or quantitative (41\%) description of the plant species composition within the burn unit (Figure 2A). One third (33\%) of studies provided no details on the soils associated with the burn units. Most (73\%) studies reported some measure of climate; 70 and $3 \%$ reported long-term climate data or climate zones, respectively (Figure 2B). Just 13\% of studies reported post-fire climatic data. A majority (70\%) of studies reported at least one metric describing burn unit topography, with elevation being the most frequently reported topographic descriptor (63\%), followed by slope (35\%) and aspect (29\%) (Figure 2C). Authors reported historic land use and disturbance legacies in $80 \%$ of studies.

Only $54 \%$ of the prescribed fire experiments evaluated provided details on the ignition characteristics (Figure 3A). The ignition method, ignition pattern, and ignition technique were reported in 27,33 , and $39 \%$ of studies, respectively. The duration of ignition was reported less often, with only $3 \%$ of studies providing this information.

Almost all studies (98\%) provided a description of the fuel complex, with $60 \%$ relying primarily on a qualitative description of the fuels present (Figure 3B). Around 2\% of all studies reported a standard fire behavior fuel model to describe the fuel complex, whereas $36 \%$ of studies provided a quantitative description of the fuel complex, with fuel loading being the most used metric (Figure 3B). Less than half (47\%) of the studies reported the burning conditions, including wind speed, temperature, relative humidity, and fuel moisture during the experiments (Figure 3C). Less than $40 \%$ of studies reported relative humidity and air temperature, and 36\% provided an estimate of the wind speed (Figure 3C). Fuel moisture content was infrequently described, with only $22 \%$ of studies providing data, of which $14 \%$ provided multiple fuel moisture categories and $8 \%$ provided a single estimate. Only $17 \%$ of studies included critical details on the meteorological observations, including the location of data collection or instruments used for fire weather measurements, and only $11 \%$ reported the sampling procedures (i.e., frequency of sampling or averaging procedures).

Our results indicate that only $30 \%$ of studies provided a metric of fire behavior such as flame length, residence time, or rate of fire spread, and only $10 \%$ of studies provided more than one metric (Figure 3D). Flame length was the most reported metric $(21 \%)$, followed by rate of spread $(11 \%)$, and residence time (11\%) (Figure 3D). Only $11 \%$ of all studies described the instrumentation, sampling design, or calculations used to estimate fire behavior information.

\section{DISCUSSION}

The ecological effects of prescribed fire arise through a suite of complex interactions between how the fire was ignited, the burning conditions, the fuel complex, and a host of other regulating effects such as climate and terrain (O'Brien et al., 2018; Bridges et al., 2019). Given the complexity of factors influencing prescribed fire effects, it is imperative that sufficient detail is reported. In our analysis and collective experience, there are substantial opportunities to invigorate how we describe methodology and report data for ecological research that involves prescribed fire experiments.

Our review found insufficient reporting of spatial location and timing data. Published studies that did not provide precise spatial locations either presented maps with reference points or a written description of the prescribed fire location. Consistent with our findings, precise spatial locations were often not reported in landscape ecology studies (Vetter et al., 2016). Although 39\% of 

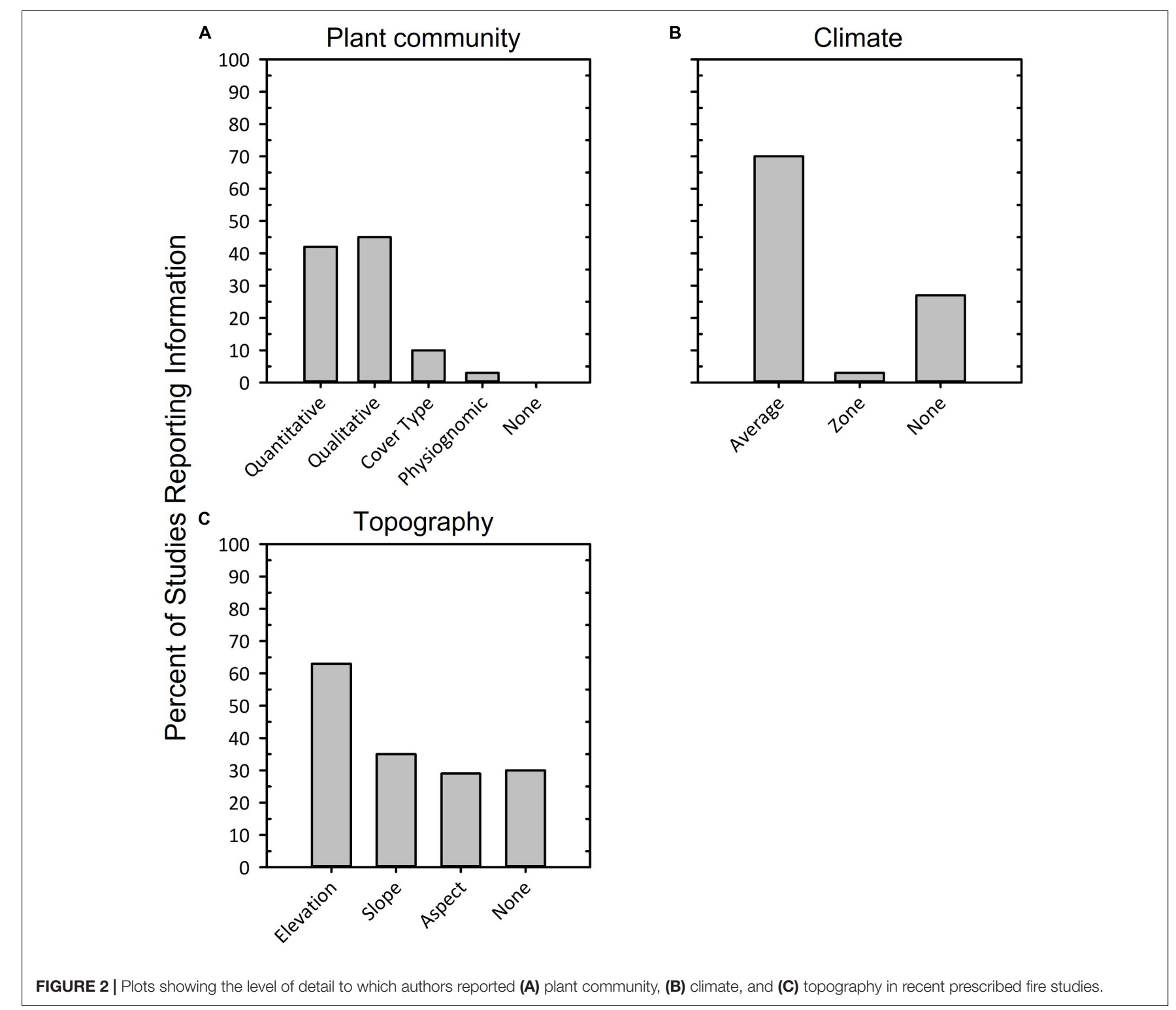

studies reported the specific day and/or time for each prescribed fire, it was more common for temporal data to be reported with less precision. Reporting a finer temporal resolution can better account for potentially confounding temporal effects (e.g., seasonality) with other variables such as plant phenology or diel moisture dynamics (Knapp et al., 2009). Although providing less precise location and temporal data may be adequate for orienting the reader to the general area and conditions of the experiment, it may not be sufficient to allow scientists to link the results with other data sources, including vegetation and land cover, fire weather, climate, or remotely sensed data. This lack of precision thus limits the application of the information collected.

A host of biotic and abiotic factors independently and jointly influence prescribed fire effects across spatial and temporal scales. At a minimum, capturing the extent and location of burned areas is critical since fires often burn as a mosaic and whether a location received fire or not is obviously essential information. For example, the amount, extent, and pattern of post-fire recruitment in conifer forests of western North America are influenced by complex interactions among the fire severity, previous and future climatic conditions, soil characteristics, aspect, and elevation (Crotteau et al., 2013; Ziegler et al., 2017; Boucher et al., 2019; Stevens-Rumann and Morgan, 2019). Our analysis found that it was common for studies to report on the long-term climatic averages, plant species composition, the underlying soil characteristics, and the land use legacies within the area burned. However, other crucial explanatory factors, including topography and quantitative measures of the plant species composition, were less frequently reported. Despite recognizing the critical role that ecological context and landscape position play in shaping ecological function and the success of land management treatments, such context is often not reported with enough detail 


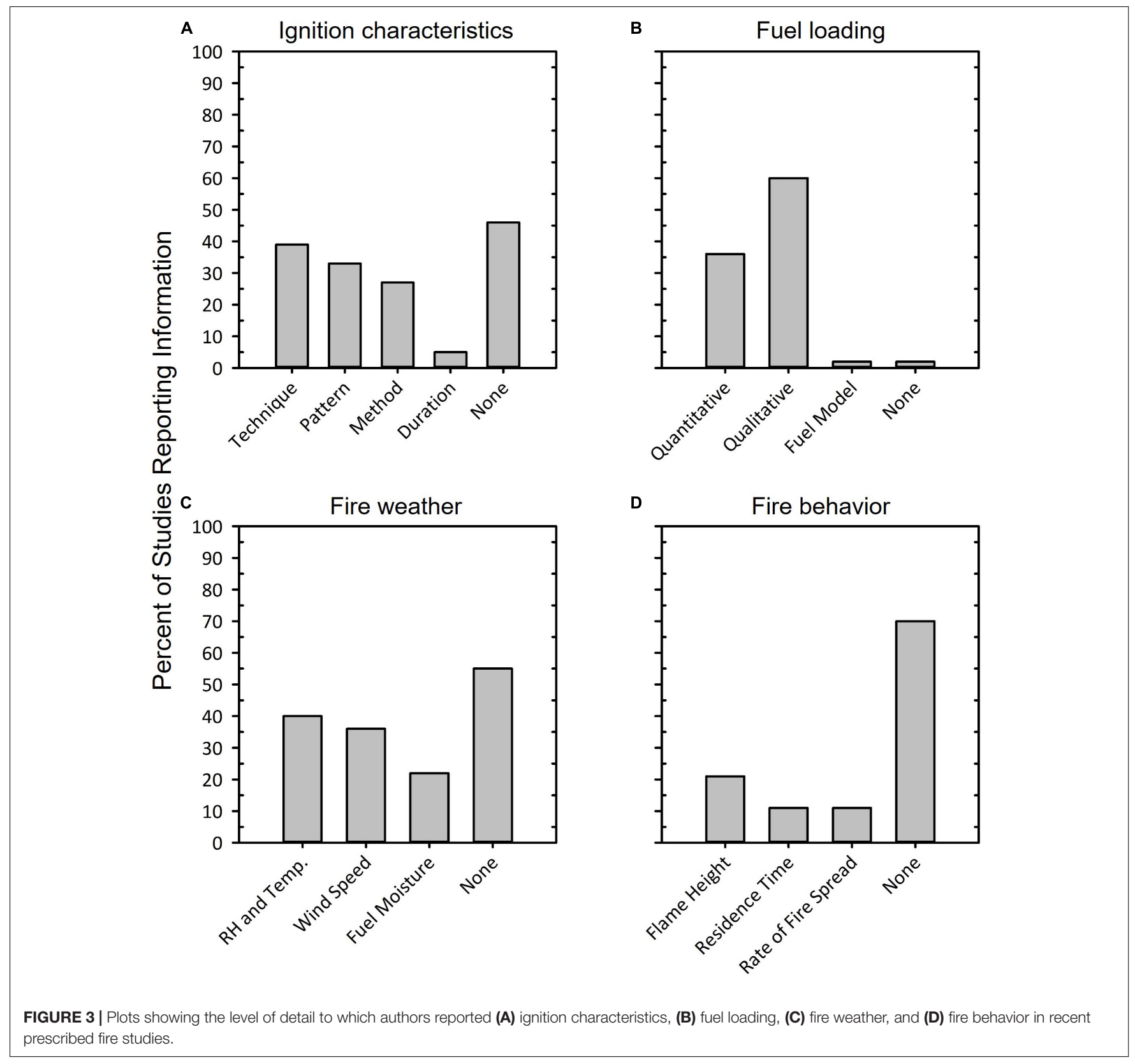

to support research syntheses or explain discrepancies among ecological studies (Vetter et al., 2016).

One of the most salient features of prescribed fires is that practitioners intentionally ignite them. This allows managers and scientists to carefully plan when, where, under which conditions, and how to ignite a fire. During this pre-burn planning period, scientists have ample opportunity to work with managers to ensure that they integrate pre-, active, and postfire data collection in a way that allows for linkages among the fuel complex, topography, weather, ignition characteristics, fire behavior, and fire effects. In contrast to wildfires, these advantages offer tremendous promise to improve our understanding of the linkages between fuels, fire weather, fire behavior, and their consequent ecological effects (O'Brien et al., 2018; Hiers et al., 2020). Using our findings as a call-to-action will help guide formerly disparate experiments toward a more holistic understanding of wildland fire.

Despite broad recognition that the ignition characteristics, fuels, and burning conditions are critical for understanding prescribed fire effects (Knapp et al., 2009; Vaillant et al., 2009; Clements et al., 2015; O’Brien et al., 2018), these variables are rarely reported. Martinson and Omi (2013) also found a lack of reporting on burning conditions which prevented them from including these as factors in their meta-analysis of fuel treatment efficacy. Similarly, a minority of studies (36\%) went beyond broad descriptions of the plant species composition and reported 
quantitative data such as fuel loading. Fuel load estimates were commonly reported as stand scale means, which inherently average out many of the spatial and temporal characteristics of the fuel complex that explain local prescribed fire behavior and effects (O’Brien et al., 2018). Additionally, few studies reported local fire behavior, which often are the mechanisms driving fire effects.

Given these findings, we present recommendations for minimum reporting standards for prescribed fire experiments (Table 2). These standards are based in part on various existing manuals and procedures for documenting and reporting prescribed fire observations (e.g., Fischer, 1978). We intend for these recommendations to be a starting point that can be used by authors, reviewers, and editorial boards to increase the quality and replicability of ecological prescribed fire science. We fully acknowledge that different studies have specific needs and resources and that any added requirements will place a burden on the primary authors. However, given that many land management agencies have procedures in place that require the collection of much of these data (e.g., Alexander and Thomas, 2003; USDI National Park Service, 2003; Fernandes and Botelho, 2004; Australasian Fire and Emergency Service Authorities Council, 2016), these standards should not impede prescribed fire experimentation. Our hope is that implementation of these standards will support the co-production of knowledge and ultimately foster actionable science.

We grouped our recommendations into three broad categories: (1) location and timing of prescribed fire experiments; (2) ecological context, landscape position, and land use legacies; and (3) ignition and burning characteristics.

\section{Location and Timing of Prescribed Fire Experiments}

Given that prescribed fire effects and ecosystem response can be highly variable at fine spatial scales (Hiers et al., 2009; Mugnani et al., 2019), we suggest that authors report coordinates for each experimental burn unit with a precision of seconds or $30 \mathrm{~m}$ resolution (Vetter et al., 2016), along with a clear description of the unit size and shape. Ideally, supplying spatial data (such as a shapefile) for each burn unit and specific coordinates for any sampling locations within burn units is helpful and can be included as "supplementary data". In some cases, such as those dealing with endangered species, excluding precise locations may be permissible if the authors can provide specific instructions for how others looking to replicate the experiment or use the data for synthesis can gain access (Vetter et al., 2016). Lastly, giving the exact timing for each burn unit, including the hour, day, month, and year of ignition, enhances the usefulness of the study to researchers and managers.

The inclusion of more precise data on the location and time of the prescribed fire experiment would allow researchers to extemporaneously connect the study to covariates describing the ecological context and landscape positioning, topography, climate, fuels, and weather conditions not reported in the original study. Additionally, such reporting may be useful in assessing the experiment's overall representativeness with respect to environmental and socioeconomic context and if geographic bias in site selection occurred (Gerstner et al., 2017). The ability to link experimental burn datasets to other data through spatial and temporal information will facilitate the development of new understandings, across and between ecosystems and sets of conditions.

\section{Ecological Context, Landscape Position, and Land Use Legacies}

Reporting data on the ecosystem burned, the landscape position of the burn unit, and any land use legacies that frame critical fire outcomes is foundational for the interpretation of study results, identifying causes of variation among studies, ensuring replicability, and furthering the potential usefulness of the study in quantitative syntheses (Haddaway and Verhoeven, 2015; Gerstner et al., 2017; Halbritter et al., 2020). We focused our suggestions on five descriptors that scientists commonly recognize as critical factors in ecological studies: the plant community; topographic characteristics such as elevation, slope, and aspect; the long term climate; soils; and land use legacies.

Plant community descriptions should characterize the assemblage of plants that occur in the study area, as well as any unique features such as invasive species. Ideally, plant community descriptions will go beyond reporting species composition and describe the horizontal and vertical structure of the vegetation with metrics such as height, diameter, density, basal area, or cover. Authors can enhance site descriptions by giving ranges in the elevation, slope, and aspect, and providing data on long-term climatic averages, soils, and land use legacies such as disturbance history. This should include a description of the disturbance history, including the type of disturbance and information on the timing, extent, and severity. In cases of chronic rather than acute disturbance, we suggest authors give estimates of extent, severity, or intensity. When reporting data from external databases, such as climate data, land cover, or soil type, we recommend that authors include citations or attributions to the source data or follow other best practice guidelines, such as Morueta-Holme et al. (2018).

We recognize that our minimum recommendations for reporting on ecological context, landscape position, and land use legacies may not be directly related to the objectives of any given study, nor are they necessarily the most important or useful contextual details. While we recommend primary authors still report on these details, ideally authors should expand on these to include information on any contextual details that help in the interpretation of the results and improve replicability of experimental findings. Although most studies provide these details for a burn unit, it would be ideal if authors also report variations among sampling locations either in the text or as "supplementary data".

\section{Ignition Characteristics and Burning Conditions}

Given their relative importance, we recommend that authors include data on the methods of ignition, the pattern of ignition, and the ignition technique. Ideally, details including the number of ignitors and the rate and duration of ignition, would also 
TABLE 2 | Suggested best practices for reporting on ecological prescribed fire experiments.

\begin{tabular}{|c|c|c|}
\hline & Minimum recommendation & Ideal recommendation \\
\hline \multicolumn{3}{|c|}{ Location and Timing } \\
\hline Coordinates & $\begin{array}{l}\text { Provide a description of unit size and shape along with } \\
\text { coordinates for each burn unit }\end{array}$ & $\begin{array}{l}\text { Publish a shapefile for each burn unit and } \\
\text { coordinates for sampling locations as } \\
\text { supplemental }\end{array}$ \\
\hline Timing & $\begin{array}{l}\text { Report the time, day, month, and year of ignition for each } \\
\text { burn unit }\end{array}$ & - \\
\hline \multicolumn{3}{|c|}{ Ecological context, Landscape position, and Land use legacies } \\
\hline Plant community & $\begin{array}{l}\text { Characterize the assemblage of plants present in the burn } \\
\text { unit prior to burning, including any distinguishing features }\end{array}$ & $\begin{array}{l}\text { Include quantitative measures of the horizontal } \\
\text { and vertical structure of the vegetation }\end{array}$ \\
\hline Topography & $\begin{array}{l}\text { Report elevation, slope, and aspect for each burn unit, } \\
\text { along with any significant topographic features or deviations }\end{array}$ & - \\
\hline Climate & $\begin{array}{l}\text { Report long-term climatic averages (10-30 years) for each } \\
\text { burn unit. Mention any significant climatic periods or events, } \\
\text { such as drought }\end{array}$ & - \\
\hline Soils & $\begin{array}{l}\text { Provide a description of the soil in a burn unit, such as soil } \\
\text { type or texture }\end{array}$ & - \\
\hline Land use legacies & $\begin{array}{l}\text { Report any past or present disturbances and land uses, } \\
\text { when they occurred, and to what extent and severity }\end{array}$ & - \\
\hline \multicolumn{3}{|c|}{ Ignition characteristics and Burning conditions } \\
\hline Ignition & $\begin{array}{l}\text { Report method of ignition, pattern of ignition, and the } \\
\text { ignition technique }\end{array}$ & $\begin{array}{l}\text { Report number of ignitors and the duration of } \\
\text { ignition and/or a shapefile of the ignition pattern }\end{array}$ \\
\hline Fuel loading & $\begin{array}{l}\text { Provide estimates for the fuel load by fuel layer (i.e., ground, } \\
\text { surface, and canopy) }\end{array}$ & Report fuel load estimates by fuel component \\
\hline Fire weather & $\begin{array}{l}\text { Report wind speed and direction, air temperature, relative } \\
\text { humidity, and fuel moisture for each burn }\end{array}$ & - \\
\hline Fire behavior & $\begin{array}{l}\text { Qualitatively or quantitatively describe spatial pattern of } \\
\text { burned areas and one or more metrics of fire behavior }\end{array}$ & $\begin{array}{l}\text { Qualitatively or quantitatively describe spatial } \\
\text { pattern of burned areas with multiple metrics of } \\
\text { fire behavior related to fuel consumption and/or } \\
\text { energy flux }\end{array}$ \\
\hline
\end{tabular}

be included in the "Materials and Methods" section or as a "supplementary data" file (Figure 4A). In addition to a description of the plant community within the burn area, we also suggest that the authors supply quantitative data describing the fuels in each layer. We suggest reporting the fuel load for both the surface and ground fuel layers, and either the canopy fuel load or bulk density, along with the canopy base height (Figure 4B). Authors should provide a minimum estimate of the fuel moisture content by fuel layer or dominant vegetation type. Ideally, authors would include quantitative fuel descriptions and fuel moisture contents, including some measure of variability, for each fuel component. Also, given the array of options for fuel sampling, it is critical that authors report their sampling design and methods (Keane, 2012).

Quantitative data on the fire weather observed during the active fire period is critical for authors to include in publications. Fire practitioners often measure weather data, yet authors rarely include this critical information. We suggest that authors report the mean and variability in wind velocity, air temperature, and relative humidity for each experimental prescribed fire. The type of instrument used, the location and frequency of sampling, and any averaging procedures should also be reported (Figure 4C).
Any relevant shifts or changes in the wind conditions during the burns are also of interest. In cases where authors rely on data from a meteorological station to obtain fire weather data, they should report the station latitude, longitude, elevation, and identifier along with information on how to access the data.

Given the complexity of interactions that drive prescribed fire behavior and effects, it is essential to include metrics that describe the fire behavior (Figure 4D). We suggest that authors include a spatial description of the pattern of burned areas since mosaics of burned and unburned areas can be important for understanding subsequent ecological responses (Mugnani et al., 2019). Given that even in areas that burned completely there is substantial variation in fire energy release, often at fine scales (O'Brien et al., 2016), we also recommend that authors provide qualitative (e.g., ocular estimates of flame length) or quantitative estimates of fire behavior. Quantitative estimates of fire behavior are best, given that there can be low confidence associated with qualitative estimates. Fire effects, particularly those related to plant physiology (e.g., mortality, embolism, and scorching), directly link to fire intensity (O'Brien et al., 2018; Varner et al., 2021), so fire behavior metrics should ideally focus on heat release, either measured directly or inferred post hoc 

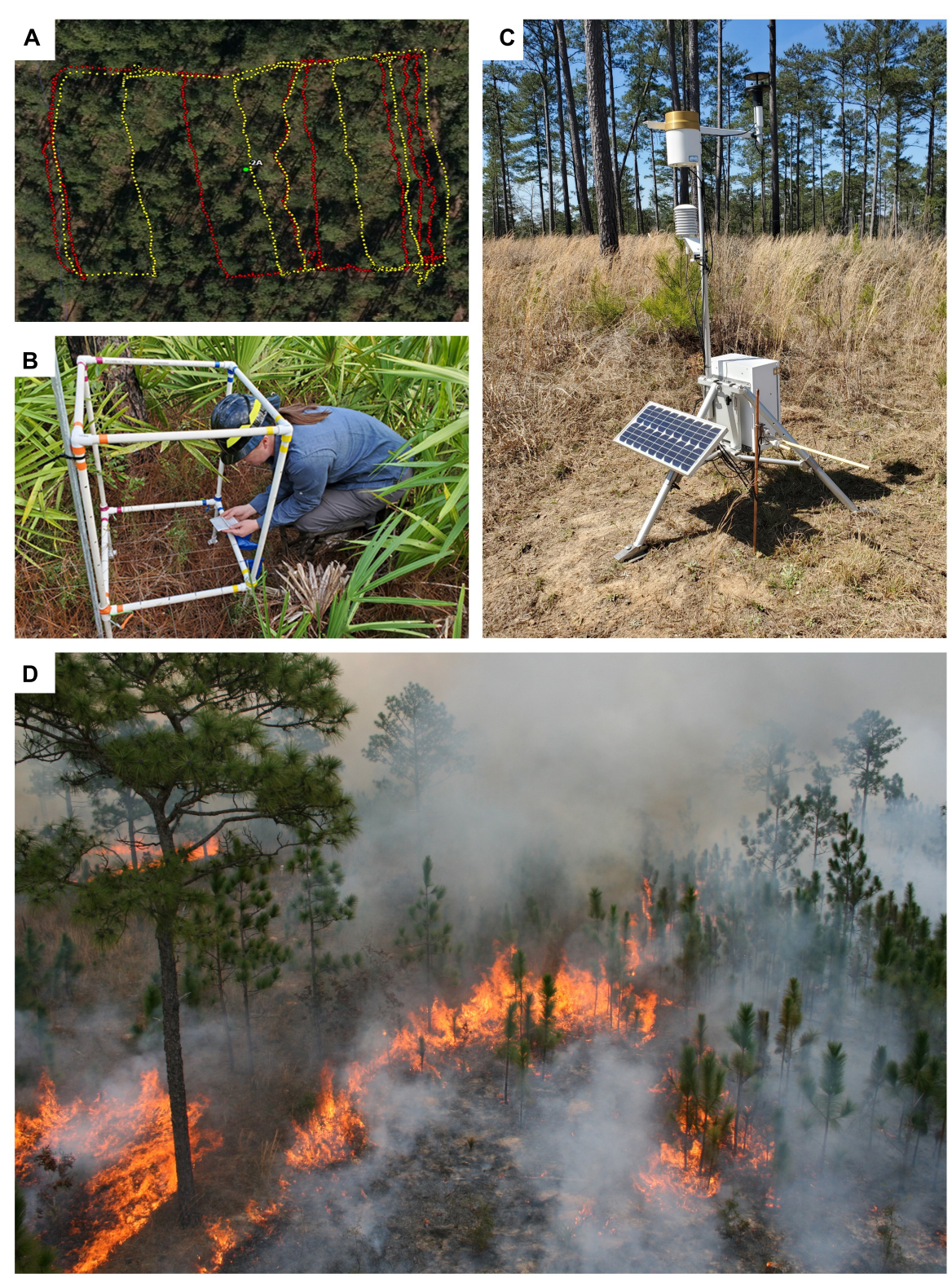

FIGURE 4 | Images of (A) Ignition pattern for an experimental prescribed fire at Tall Timbers Research Station based on GPS tracking. Ignition was conducted by two individuals (red and yellow dots) with drip torches. (B) 3-Dimensional surface fuels sampling based on the methods of Hiers et al. (2021). (C) A Campbell Scientific Remote Automated Weather Station (RAWS) used to monitor and collect data on wind speed, air temperature, relative humidity, and other meteorological conditions during prescribed burns. (D) Still shot from oblique color video of interacting fire lines during a 2012 prescribed burn at Eglin Air Force Base, Florida.

from biomass consumption. Although authors often report fire temperatures, as estimated by widely used measurement techniques such as thermocouples and temperature-sensitive paints, such approaches are not particularly valuable as temperatures are not mechanistically related to fire behavior or fire effects (Bova and Dickinson, 2008). Extensive documentation on fire variable terminology, instrumentation, measurements, and data resources is available in National Wildfire Coordinating Group (2014). Reporting relevant fire behavior metrics, in conjunction with the fuels complex, fire weather, and the ecological and landscape characteristics can often provide better explanations for prescribed fire effects rather than relying solely on the pre-fire ecological and landscape conditions.

\section{CONCLUSION}

As fire scientists worldwide strive to develop new predictive modeling tools and acquire a deeper mechanistic and empirical understanding of prescribed fires, knowing the details of these experiments is critical. Our analysis of top journals showed that 
insufficient reporting of critical details is pervasive within the literature. Although we were not able to identify the reasons for the lack of reporting, our collective experience is that much of the data required to meet these recommendations is often collected during prescribed fires, indicating that a lack of reporting could be because data was not transferred from managers to researchers or was simply disregarded during manuscript preparation or revision. Regardless of the reasons for underreporting, the lack of methodological detail impedes the replication of prescribed fire studies, verification and comparison of their results, and decreases the potential for insights derived from meta-analyses. To combat this, we presented a list of suggested reporting standards for ecological prescribed fire studies. We believe that these minimum standards could be a starting point for more consistent and rigorous interpretation of research results. In some cases, the additional resources of meeting these requirements may encourage scientists to develop meaningful linkages with managers conducting prescribed fires and stimulate the coproduction of knowledge within prescribed fire research. It is our hope that these suggestions promote future quantitative research syntheses, increase the quality and replicability of ecological prescribed fire experiments, and ultimately foster actionable science.

Although the focus of this study was on evaluating ecological prescribed fire experiments, our recommendations could generally be useful to improve the quality and value of primary research studies within wildland fire sciences more broadly. For example, studies focused on the ecological effects of wildfires and managed wildfires would benefit from reporting the location and time of burn (and daily fire progression), ecological context, landscape position, and the burning conditions within these fires. The expansion of our suggestions to wildfires could also help foster needed synthesis across prescribed fire and wildfire literature. Similarly, studies that seek to understand the cumulative effect of multiple fires over time could benefit from understanding the characteristics of each fire rather than solely focusing on the net effect of multiple burns. Finally, more comprehensive reporting of the burning conditions, fuel

\section{REFERENCES}

Alexander, M. E., and Thomas, D. A. (2003). Wildland fire behavior case studies and analyses: other examples, methods, reporting standards, and some practical advice. Fire Manag. Today 63, 4-12.

Anderson, H. E. (1982). Aids To Determining Fuel Models For Estimating Fire Behavior. General Technical Report INT-122. Ogden, UT: USDA Forest Service, Intermountain Forest and Range Experiment Station.

Australasian Fire and Emergency Service Authorities Council (2016). National Guidelines For Prescribed Burning Operations. Report for National Burning Project - Subproject 4. Melbourne, VIC: Australasian Fire and Emergency Service Authorities Council Limited.

Boucher, D., Gauthier, S., Thiffault, N., Marchand, W., Girardin, M., and Urli, M. (2019). How climate change might affect tree regeneration following fire at northern latitudes: a review. New For. 51, 543-571. doi: 10.1007/s11056-01909745-6

Bova, A. S., and Dickinson, M. B. (2008). Beyond "fire temperatures": calibrating thermocouple probes and modeling their response to surface fires in hardwood fuels. Can. J. For. Res. 38, 1008-1020. doi: 10.1139/X07-204 complexes, and fire behavior could facilitate model development and evaluation (Hoffman et al., 2016). Improving wildland fire research via invigorated standards offers tremendous promise for moving prescribed fire applications forward and opening this expanding scientific area to more rigorous future analyses.

\section{AUTHOR CONTRIBUTIONS}

$\mathrm{SB}, \mathrm{CH}, \mathrm{JK}$, and JMV conceived the original idea, performed the literature review, and wrote the manuscript. $\mathrm{HR}$ and WT performed the literature review and contributed to the manuscript. JH, JO'B, RL, NS, RP, and CS contributed ideas on the manuscript structure and analyses. All authors contributed to the article and approved the submitted version.

\section{FUNDING}

This work was funded by SERDP Awards RC19-1119 (PI: CH) and RC20-1025 (PI: RP).

\section{ACKNOWLEDGMENTS}

This work was based on our collective frustration with peer reviews and interpretability of past published research. We thank S. Hood, A. Cansler, T. Shearman, P. van Mantgem, and J. Ziegler for past discussions. We have benefitted from conversations on this topic with many colleagues (list too long to type). We hope this article moves these discussions and our collective science forward.

\section{SUPPLEMENTARY MATERIAL}

The Supplementary Material for this article can be found online at: https://www.frontiersin.org/articles/10.3389/ffgc.2021. 750699/full\#supplementary-material

Bridges, J. M., Petropoulos, G. P., and Clerici, N. (2019). Immediate changes in organic matter and plant available nutrients of Haplic Luvisol soils following different experimental burning intensities in Damak Forest, Hungary. Forests 10:453. doi: 10.3390/f10050453

Clements, C. B., Lareau, N. P., Seto, D., Contezac, J., Davis, B., Teske, C., et al. (2015). Fire weather conditions and fire-atmosphere interactions observed during low-intensity prescribed fires - RxCADRE 2012. Int. J. Wildland Fire 25, 90-101. doi: 10.1071/WF14173

Cohen, J. (1960). A coefficient of agreement for nominal scales. Educ. Psychol. Meas. 20, 37-46. doi: 10.1177/001316446002000104

Cooke, S. J., Birnie-Gauvin, K., Lennox, R. J., Taylor, J. J., Rytwinski, T., Rummer, J. L., et al. (2017). How experimental biology and ecology can support evidence-based decision-making in conservation: avoiding pitfalls and enabling application. Conserv. Physiol. 5:cox043. doi: 10.1093/conphys/cox043

Crotteau, J., Varner, J. M., and Ritchie, M. (2013). Post-fire regeneration across a fire severity gradient in the southern Cascades. For. Eco. Manag. 287, 103-112. doi: 10.1016/j.foreco.2012.09.022

Eyre, F. H. (1980). Forest cover Types Of The United States And Canada. Washington, DC: Society of American Foresters. 
Faber-Langendoen, D., Keeler-Wolf, T., Meidinger, D., Josse, C., Weakley, A., Tart, D., et al. (2016). Classification And Description Of World Formation Types. General Technical Report RMRS-GTR-346. Fort Collins, CO: U.S. Department of Agriculture, Forest Service, Rocky Mountain Research Station, doi: 10.2737/ RMRS-GTR-346

Fernandes, P. M. (2018). Scientific support to prescribed underburning in southern Europe: what do we know? Sci. Total Environ. 630, 340-348. doi: 10.1016/j. scitotenv.2018.02.214

Fernandes, P. M., and Botelho, H. S. (2003). A review of prescribed burning effectiveness in fire hazard reduction. Int. J. Wildland Fire 12, 117-128. doi: 10.1071/wf02042

Fernandes, P., and Botelho, H. (2004). Analysis of the prescribed burning practice in the pine forest of northwestern Portugal. J. Environ. Manage 70, 15-26. doi: 10.1016/j.jenvman.2003.10.001

Fischer, W. C. (1978). Planning And Evaluating Prescribed Fires: A Standard Procedure. Ogden, UT: Department of Agriculture, Forest Service, Intermountain Forest and Range Experiment Station.

Gerstner, K., Moreno-Mateos, D., Gurevitch, J., Beckmann, M., Kambach, S., Jones, H. P., et al. (2017). Will your paper be used in a meta-analysis? Make the reach of your research broader and longer lasting. Methods Ecol. Evol. 8, 777-784.

Haddaway, N. R., and Verhoeven, J. T. A. (2015). Poor methodological detail precludes experimental repeatability and hampers synthesis in ecology. Ecol. Evol. 5, 4451-4454. doi: 10.1002/ece3.1722

Halbritter, A. H., Boeck, H. J. D., Eycott, A. E., Reinsch, S., Robinson, D. A., Vicca, S., et al. (2020). The handbook for standardized field and laboratory measurements in terrestrial climate change experiments and observational studies (ClimEx). Methods Ecol. Evol. 11, 22-37.

Hiers, J. K., O’Brien, J. J., Mitchell, R. J., Grego, J. M., Loudermilk, E. L., Hiers, J. K., et al. (2009). The wildland fuel cell concept: an approach to characterize finescale variation in fuels and fire in frequently burned longleaf pine forests. Int. J. Wildland Fire 18, 315-325. doi: 10.1071/WF08084

Hiers, J. K., O’Brien, J. J., Varner, J. M., Butler, B. W., Dickinson, M., Furman, J., et al. (2020). Prescribed fire science: the case for a refined research agenda. Fire Ecol. 16:11. doi: 10.1186/s42408-020-0070-8

Hiers, Q. A., Loudermilk, E. L., Hawley, C. M., Hiers, J. K., Pokswinski, S., Hoffman, C. M., et al. (2021). Non-destructive fuel volume measurements can estimate fine-scale biomass across surface fuel types in a frequently burned ecosystem. Fire 4:36. doi: 10.3390/fire 4030036

Hillebrand, H., and Gurevitch, J. (2013). Reporting standards in experimental studies. Ecol. Lett. 16, 1419-1420. doi: 10.1111/ele.12190

Hoffman, C. M., Canfield, J., Linn, R. R., Mell, W., Sieg, C. H., Pimont, F., et al. (2016). Evaluating crown fire rate of spread predictions from physics-based models. Fire Technol. 52, 221-237. doi: 10.1007/s10694-015-0500-3

Hunter, M. E., Colavito, M. M., and Wright, V. (2020). The use of science in wildland fire management: a review of barriers and facilitators. Curr. For. Rep. 6, 354-367. doi: 10.1007/s40725-020-00127-2

Keane, R. E. (2012). Describing wildland surface fuel loading for fire management: a review of approaches, methods and systems. Int. J. Wildland Fire 22, 51-62. doi: 10.1071/WF11139

Knapp, E., Estes, B., and Skinner, C. (2009). Ecological Effects Of Prescribed Fire Season: A Literature Review And Synthesis For Managers. JFSP Synth. Rep. Available online at: https://digitalcommons.unl.edu/jfspsynthesis/4 (accessed June 1, 2021).

Landis, J. R., and Koch, G. G. (1977). An application of hierarchical kappa-type statistics in the assessment of majority agreement among multiple observers. Biometrics 33, 363-374. doi: 10.2307/2529786

Martinson, E. J., and Omi, P. N. (2013). Fuel Treatments And Fire Severity: A MetaAnalysis. Ft. Collins, CO: U.S. Department of Agriculture, Forest Service, Rocky Mountain Research Station, doi: 10.2737/RMRS-RP- 103

Morueta-Holme, N., Oldfather, M. F., Olliff-Yang, R. L., Weitz, A. P., Levine, C. R., Kling, M. M., et al. (2018). Best practices for reporting climate data in ecology. Nat. Clim. Change 8, 92-94. doi: 10.1038/s41558-017-0060-2

Mugnani, M. P., Robertson, K. M., Miller, D. L., and Platt, W. J. (2019). Longleaf pine patch dynamics influence ground-layer vegetation in old-growth pine savanna. Forests 10:389. doi: 10.3390/f10050389

National Wildfire Coordinating Group (2014). Fire Behavior Field Reference Guide, $P M S$ 437. Available online at: https://www.nwcg.gov/publications/pms437 [Accessed September 21, 2021].
O’Brien, J. J., Hiers, J. K., Varner, J. M., Hoffman, C. M., Dickinson, M. B., Michaletz, S. T., et al. (2018). Advances in mechanistic approaches to quantifying biophysical fire effects. Curr. For. Rep. 4, 161-177. doi: 10.1007/ s40725-018-0082-7

O’Brien, J. J., Loudermilk, E. L., Hornsby, B., Hudak, A. T., Bright, B. C., Dickinson, M. B., et al. (2016). High-resolution infrared thermography for capturing wildland fire behaviour: RxCADRE 2012. Int. J. Wildland Fire 25:62. doi: 10. 1071/WF14165

Ottmar, R. D. O. D., Sandberg, D. V. S. V., Riccardi, C. L. R. L., and Prichard, S. J. P. J. (2007). An overview of the fuel characteristic classification system quantifying, classifying, and creating fuelbeds for resource planning. Can. J. For. Res. 37, 2383-2393. doi: 10.1139/X07-077

Pullin, A. S., Knight, T. M., Stone, D. A., and Charman, K. (2004). Do conservation managers use scientific evidence to support their decision-making? Biol. Conserv. 119, 245-252. doi: 10.1016/j.biocon.2003.11.007

Reichman, O. J., Jones, M. B., and Schildhauer, M. P. (2011). Challenges and opportunities of open data in ecology. Science 331, 703-705. doi: 10.1126/ science. 1197962

Ryan, K. C., Knapp, E. E., and Varner, J. M. (2013). Prescribed fire in North American forests and woodlands: history, current practice, and challenges. Front. Ecol. Environ. 11:e15-e24. doi: 10.1890/120329

Scott, J. H., and Burgan, R. E. (2005). Standard Fire Behavior Fuel Models: A Comprehensive Set For Use With Rothermel's Surface Fire Spread Model. RMRSGTR-153. Ft. Collins, CO: U.S. Department of Agriculture, Forest Service, Rocky Mountain Research Station, doi: 10.2737/RMRS-GTR-153

Stephens, S. L., Battaglia, M. A., Churchill, D. J., Collins, B. M., Coppoletta, M., Hoffman, C. M., et al. (2021). Forest restoration and fuels reduction: convergent or divergent? BioScience 71, 85-101. doi: 10.1093/biosci/ biaal 34

Stevens-Rumann, C. S., and Morgan, P. (2019). Tree regeneration following wildfires in the western US: a review. Fire Ecol. 15, 15. doi: 10.1186/s42408019-0032-1

USDI National Park Service (2003). Fire Monitoring Handbook. Boise, ID: National Interagency Fire Center.

Vaillant, N. M., Fites-Kaufman, J. A., and Stephens, S. L. (2009). Effectiveness of prescribed fire as a fuel treatment in Californian coniferous forests. Int. J. Wildland Fire 18, 165-175. doi: 10.1071/WF06065

Varner, J. M., Hood, S. M., Aubrey, D. P., Yedinak, K., Hiers, J. K., Jolly, W. M., et al. (2021). Tree crown injury from wildland fires: causes, measurement, and ecological and physiological consequences. New Phytol. 231, 1676-1685. doi: 10.1111/nph.17539

Vetter, D., Storch, I., and Bissonette, J. A. (2016). Advancing landscape ecology as a science: the need for consistent reporting guidelines. Landsc. Ecol. 31, 469-479. doi: 10.1007/s10980-015-0296-z

Whitlock, M. C. (2011). Data archiving in ecology and evolution: best practices. Trends Ecol. Evol. 26, 61-65. doi: 10.1016/j.tree.2010.11.006

Ziegler, J. P., Hoffman, C. M., Fornwalt, P. J., Sieg, C. H., Battaglia, M. A., Chambers, M. E., et al. (2017). Tree regeneration spatial patterns in ponderosa pine forests following stand-replacing fire: influence of topography and neighbors. Forests 8:391. doi: 10.3390/f8100391

Conflict of Interest: The authors declare that the research was conducted in the absence of any commercial or financial relationships that could be construed as a potential conflict of interest.

Publisher's Note: All claims expressed in this article are solely those of the authors and do not necessarily represent those of their affiliated organizations, or those of the publisher, the editors and the reviewers. Any product that may be evaluated in this article, or claim that may be made by its manufacturer, is not guaranteed or endorsed by the publisher.

Copyright (ㄷ 2021 Bonner, Hoffman, Kane, Varner, Hiers, O’Brien, Rickard, Tinkham, Linn, Skowronski, Parsons and Sieg. This is an open-access article distributed under the terms of the Creative Commons Attribution License (CC BY). The use, distribution or reproduction in other forums is permitted, provided the original author(s) and the copyright owner(s) are credited and that the original publication in this journal is cited, in accordance with accepted academic practice. No use, distribution or reproduction is permitted which does not comply with these terms. 